\title{
PEYNİR KÜFÜ OLARAK PENICILLIUM ROQUEFORTPNIN TAKSONOMİSİ, MORFOLOJİK, GENETİK VE METABOLİK ÖZELLİKLERİ
}

\author{
Hatice Ebrar Krrtıl ${ }^{1 *} *$, Banu Metin ${ }^{1,2}$, Muhammet Arıc1 ${ }^{3}$ \\ ${ }^{1}$ İstanbul Sabahattin Zaim Üniversitesi, Mühendislik ve Doğa Bilimleri Fakültesi, Gıda Mühendisliği Bölümü, \\ İstanbul, Türkiye \\ 2İstanbul Sabahattin Zaim Üniversitesi, Gıda ve Tarım Uygulama ve Araştırma Merkezi, İstanbul, Türkiye \\ ${ }^{3}$ Yıldız Teknik Üniversitesi, Kimya-Metalürji Fakültesi, Gıda Mühendisliği Bölümü, İstanbul, Türkiye
}

Geliş / Received: 17.07.2020; Kabul / Accepted: 07.11.2020; Online bask1 / Published online: 20.11.2020

Kırtıl, H.E., Metin, B., Arıc1, M. (2020). Peynir küfü olarak Penicillium roquefortìnin taksonomisi, morfolojik, genetik ve metabolik özellikleri. GIDA (2020) 45 (6): 1188-1200 doi: 10.15237/ gida.GD20091

Kirtıl, H.E., Metin, B., Arnc, M. (2020). Taxonomy, morphological, genetic and metabolic characteristics of Penicillium roqueforti as a cheese mold. GIDA (2020) 45 (6): 1188-1200 doi: 10.15237/gida.GD20091

\section{ÖZ}

Filamentli bir fungus olan Penicillium roqueforti, küflü peynirlerin olgunlaştrilmasında sekonder starter olarak kullanılmaktadır. Starter kültür olarak kullanılan işletmelerde, $P$. roqueforti direkt olarak süt içine katılabildiği gibi, peynir pıhtısı üzerine püskürtülerek de inoküle edilmektedir. Ticari starter kültür kullanılmadığında ise ortamdan bulaşarak peynirde spontan olarak gelişebilir. Son yllarda, P. roquefortỉnin morfolojik, metabolik ve genetik özellikleri ile ilgili çalışmalar yapılmıştı. Mağara ya da mahzen ortamından gelen P. roquefortỉnin peynir matriksine adaptasyonu ve yüzylllar süren evcilleşme süreci hakkında yeni bulgular ortaya çıkmıştır. Ayrıca, P. roquefortìnin eşeyli üreme yapabildiği tespit edilmiştir ki, bunun biyoteknolojik açıdan büyük önemi söz konusudur. Bu derlemede, gida endüstrisi için değerli bir tür olan P. roquefort’ nin taksonomik, morfolojik, genetik ve metabolik özellikleri sunulmuş, bu özelliklerin küflü peynir üretiminde kullanımı değerlendirilmiş ve $P$. roquefortin nin biyoteknolojik potansiyeli vurgulanmıştur.

Anahtar kelimeler: Penicillium roqueforti, küflü peynir, starter kültür, taksonomi, genetik özellikler

\section{TAXONOMY, MORPHOLOGICAL, GENETIC AND METABOLIC CHARACTERISTICS OF PENICILLIUM ROQUEFORTI AS A CHEESE MOLD}

\begin{abstract}
Penicillium roqueforti is a filamentous fungus used as secondary starter culture in mold-ripening of cheese. In facilities using starter cultures, $P$. roqueforti is added directly in milk or introduced by spraying on the cheese curd. If a commercial starter is not used, the fungus can spontaneously grow on cheese through contamination from the environment. In recent years, studies on morphological, metabolic, and genetic characteristics of $P$. roqueforti have been conducted. New findings have been reported on the adaptation of $P$. roqueforti that originates from caves or cellars, to cheese matrix and the domestication process that has been going on for centuries. In addition, this species was found to be able to reproduce sexually, which is of great biotechnological importance. In this review, taxonomic, morphological, genetic, and metabolic features of $P$. roqueforti are presented, the use of
\end{abstract}

${ }^{*}$ Yazışmalardan sorumlu yazar/Corresponding author:

$\bowtie$ : hatice.kirtil@izu.edu.tr

(2): (+90) 2126929820

冝: (+90) 2126938229

Hatice Ebrar Kırtıl; ORCID no: 0000-0003-0784-4452

Banu Metin; ORCID no: 0000-0002-3203-0058

Muhammet ArICl; ORCID no: 0000-0003-4126-200X 
these characteristics in cheese production and the biotechnological potential of $P$. roqueforti is emphasized.

Keywords: Penicillium roqueforti, mold-ripened cheeses, starter culture, taxonomy, genetic characteristics

\section{GİRİ̧̧}

Ascomycetes'lerin (altşube, sinıf, takım; Perizomycotina, Eurotiomycetes, Eurotiales) Aspergillaceae ailesinin yaklaşık 354 Penicillium türü arasinda yer alan Penicillium roqueforti, özellikle Rokfor, Stilton, Danablu, Gorgonzola ve Blauschimmelkæse gibi mavi-damarli peynirlerle ilișkilendirilen, ayrıca tahıl, yem, toprak gibi peynir harici izolasyon kaynakları olan saprotrof, filamentli bir fungustur (Frisvad ve Samson; 2004; Visagie vd., 2014). P. roqueforti, ülkemizde üretilen Erzurum Küflü Civil, Divle Obruk ve Konya Küflü gibi küflü peynirlerden de izole edilerek tanımlanmıștır (Cakmakçı vd., 2012; Öztürkoğlu Budak, 2016; Kırtıl, 2018; Seri, 2020). İlk olarak, $P$. roqueforti Thom adiyla peynirden izole edilmiştir. $P$. roquefortìnin identifikasyonunda önceleri morfolojisi ve ürettiği metabolitler kullanılmıstır (Frisvad ve Samson, 2004). Son yıllarda bu türün tanımlanmasında ve çeşitliliğinin belirlenmesinde moleküler teknikler (rastgele çoğaltılmış polimorfik DNA (RAPD), ribozomal RNA (rRNA) dizileme, multilokus dizi tiplendirme (MLST) vb.) kullanılmaktadır (Geisen vd., 2001; Fernandez-Bodega vd., 2009; Visagie vd., 2014; Gillot vd., 2015). Bu türün, taksonomik olarak $P$. carneum, $P$. paneum ve $P$. psychrosexualis türlerine yakın olduğu tespit edilmiştir (Houbraken vd., 2010). Yakın zamanda bu seri içinde, $P$. mediterraneum olarak adlandırılan bir tür daha tanımlanmıștır (Guevara-Suarez vd., 2020).

P. roquefortinin izolasyonunda ve koloni morfolojisinin incelenmesinde Czapek Dox Agar (CDA), Czapek Yeast Agar (CYA), Kreatin Sükroz Agar (CREA), Malt Ekstrakt Agar (MEA), Potato Dekstroz Agar (PDA), Yeast Ekstrakt Sükroz Agar (YES), Oat Meal Agar (OA) besiyerleri kullanılmaktadır (Frisvad ve Samson, 2004). Fungal koloniler, CYA ve MEA besiyerlerinde 14 günde $40-70 \mathrm{~mm}$ çapına ulaşırlar. Koloniler, açık yeşilden koyu yeşile değişen tipik mavi-yeşil renktedir. Koloni yapısı, kadifemsi dokudan damarlı dokuya kadar değişebilir (Frisvad ve Samson, 2004). Gillot vd.
(2015), PDA'da $25^{\circ} C^{\prime}$ de 7 gün inkübasyon sonucu inceledikleri $P$. roqueforti suşlarının makroskopik morfolojilerinde çeşitliliğin olduğunu belirtmişlerdir. Genellikle, aseksüel spor üretmekle birlikte (Frisvad ve Samson, 2004), P. roquefortinin bazı şartlar altında eşeyli üreme yaptığ da tespit edilmiştir (Ropars vd., 2012; 2014).

P. roqueforti, gelişme şartlarına göre, bazı biyoaktif bileşikler, aroma maddeleri ve mikotoksinler gibi çok sayıda primer ve sekonder metabolit üretebilir. Peynir ortaminda $P$. roquefortinin andrastin A, B gibi antitümör etkili bileşiklerin yanı sıra; mikofenolik asit gibi antimikrobiyal ve immünsupresif özelliklere sahip metabolitleri de sentezlediği bildirilmiştir. Bu bileşiklerin yanı sıra, rokfortin C, isofumigaklavin, PR toksin gibi mikotoksinleri de ürettiği ifade edilmiştir (Frisvad ve Samson, 2004; Garcia-Estrada ve Martin, 2016; Gillot vd., 2017a; Martin ve Coton, 2017). Ancak son çalışmalarda, $P$. roqueforti’nin bazı metabolitleri peynir ortamında insan sağlığına olumsuz bir etkisinin olmayacağı kadar düşük konsantrasyonlarda ürettiği, PR toksinin de yine peynir ortamında daha az toksik başka bileşiklere dönüş̧üğü tespit edilmiştir (Hymery vd., 2014). Bu bulgular, Renaud ve Lorgeril (1992)'in ortaya attığ1 Fransız Paradoksu'nu tekrar gündeme getirmiştir. Bu paradoks, doymuş yağ içeriği yüksek bir beslenme şekline sahip Fransızların, epidemiyolojik bir çalışma sonucu kardiyovasküler hastalıklardan kaynaklanan ölümlerinin düşük oranlarda olduğunun tespit edilmesiyle ortaya atılmışıtır. Ancak, Petyaev ve Bashmakov (2012), daha sonra bu durumun Fransa'da yüksek oranlarda mavi-damarlı peynir tüketiminden gelen andrastin A, B ve mikofenolik asit gibi biyoaktif bileşiklerden kaynaklandığını öne sürmüştür. Bu bakış açısı, mavi-damarlı ya da küfle olgunlaşturlmış peynirlerin seçkin organoleptik özelliklerinin yanı sıra biyolojik açıdan da değerli olabileceğini düşündürmektedir. Peynirlerin üretiminde sekonder starter kültür olan $P$. roquefortìnin, sadece yüzeyde değil, 
peynirin içinde de üremesi istendiğinden, olgunlaşma başlangıcinda peynirde ince çubuklarla delikler açılarak küfün iç kısımlara da erişmesi ve yerleşmesi sağlanır; bu şekilde karakteristik mavi-damarlı yapiya ulaşılır. Bu tür, olgunlaşma sürecinde, geleneksel peynir üretiminde ortamdan gelip peynirde gelişebileceği gibi, ticari starter formunda da peynire inoküle edilebilir (Fox vd., 2016a; Metin, 2018). Ülkemizde üretilen Erzurum Küflü Civil, Divle Obruk, Konya Küflü, Kars Çeçil, Elazı̆̆-Bingöl Tomas, Hatay Sürk, Çömlek Tulum, Akdeniz Tulum gibi küflü peynirlerde ise daha çok geleneksel küflendirme söz konusudur (Çakmakç1, 2011; Yalman vd., 2016). Son y1llarda yapılan çalışmalarda geleneksel küflü peynirlerimizde baskın küf türünün, Avrupa tipi mavi-damarlı peynirlerdeki gibi, $P$. roqueforti olduğu tespit edilmiştir (Çakmakçı vd., 2012; Öztürkoğlu Budak, 2016; Yalman vd., 2016).

P. roqueforti’nin olgunlaştırma sürecinde peynirde baskın türü oluşturmasını, yüzyıllar boyunca peynir ortamına adaptasyonunun ve evcilleşme sürecinin sağladığı öne sürülmüştür (Gibbons ve Rinker, 2015; Bodinaku vd., 2019). P. roqueforti'nin evcilleşme süreci özellikle, muhtelemen diğer peynir mikroorganizmalarından genomuna kazandırdığ1 yatay gen transfer bölgelerinde (horizontal gene transfer, HGT) bulunan laktoz metabolizması ve antimikrobiyal özellikleri içeren CheesyTer ve Wallaby gen bölgeleriyle ilişkilendirilmiştir (Cheeseman vd., 2014; Ropars vd., 2015).

Son on y1lda, P. roqueforti'nin taksonomisi, genetik özellikleri, çeşitliliği, eşeyli üreme potansiyeli, fizyolojisi ve metabolizması ile ilgili çalışmalar yapılmış ve biyoteknolojik değeri ortaya konmuştur. Bu derlemede, bu türün morfolojisi, taksonomisi, genetiği, fizyolojisi, metabolizması ve biyoteknolojik potansiyeli ile ilgili çalışmalar incelenmiştir.

\section{P. ROQUEFORTPNIN MORFOLOJIKK ÖZELLIKLLRİ}

$P$. roquefortinin makroskopik morfolojisinin değerlendirmesinde, CDA, CYA, CREA, MEA, PDA, YES, OA gibi besiyerlerinde gösterdiği koloni şekli, yapısı/dokusu ve renkleri, koloni çapları ve eksudat oluşturma özellikleri değerlendirilmiştir (Frisvad ve Samson, 2004; Visagie vd., 2014). Koloniler, genellikle açı yeşilden koyu yeşile değişen renktedir. Koloni yapıları ise, tüylü, kadifemsi, damarlı (buruşuk) görünümlü olabilir (Frisvad ve Samson, 2004). Kolonilerin renkleri ve yapılan, besiyeri bileşimi (farklı şeker kullanımı gibi) ve inkübasyon şartlarına göre değişebilir. PDA besiyerinde $25^{\circ} \mathrm{C}$ 'de 7 gün inkübasyonu sonucu, $P$. roqueforti suşları arasında koloni rengi farklılıkları net bir şekilde tespit edilmiş ve makroskopik morfolojilerinde çeşitliliğin olduğu belirtilmiştir. $\mathrm{Bu}$ besiyerinde açık yeşilden koyu yeşile, zeytin yeşilinden donuk yeşile farklı renkli koloniler görülebilir (Gillot vd., 2015). Koloniler, MEA besiyerinde, yeşil, sar1-turuncu renk oluşturabilir. Koloni dokular1, PDA ve MEA besiyerlerinde kadifemsi-yünlü ve merkezleri bombeli yap1 gösterirken, YES besiyerinde damarlı (buruşuk) yap1 oluşabilir (Şekil 1). Ayrıca besiyerinde, kolonilerin arka kısımları ise, açık yeşil olmasının yanı sira krem, sar1, kahverengi veya turuncu renkler gösterebilir. Bazı suşlar, koloni üzerinde, hiyalin damlacıkları şeklinde eksudat denilen bir çeşit sıv1 salg1lar. Kolonilerin diş çeperinde beyaz yünsü yapılar oluşabilir. Kolonilerin çaplan ise, CYA ve MEA besiyerlerinde 14 günde 40-70 mm'ye ulaşır (Frisvad ve Samson, 2004; Visagie vd., 2014; MycoBank, 2020).

P. roqueforti’nin mikroskopik özelliklerinin incelenmesinde, miselyum ve hif yapilarına bakilır. Birden fazla hücrenin yan yana gelmesiyle oluşturdukları ipliksi yapıya hif, hif topluluğuna ise miselyum denir. Bu türü, diğer Penicillium türlerinden ayırmak için mikroskop altında hif, hif sap1, konidyofor, konidya, phialide, metula, rami/dal (Şekil 1) farklılıkları değerlendirilir (Frisvad ve Samson, 2004; Visagie vd., 2014). Ancak, P. roqueforti suşlarının mikroskobik yapılarını inceleyerek ayrım yapmak mümkün değildir. Kitinsi sert bir tabakadan oluşan hücre duvarlarının yanı sira, hif sapları (ince, uzun, saydam yapılar), septalı (bölmeli) veya septasız (bölmesiz) olabilir. Küfün gelişimi esnasında oksijen yokluğunda oluşmayan yumrular (ornamentation), oksijen varlığında hif sapları (stipe) üzerinde yer alabilir. Konidyoforlar ise; 
konidyalar, phialide, metula ve ramiden oluşan hifin baş kısmıdır. Bu kısım, 100-200 $\mu \mathrm{m}$ x 4-6,5 $\mu \mathrm{m}$ boyutlarındadır ve ikili dallanmaya (terverticillate) veya ikiden fazla dallanmaya (quaterverticillate) sahip olabilir (Şekil 1).
Konidya, 4-8 $\mu \mathrm{m}$ çapinda ve genellikle küresel şekillidir. Phialide, metula ve rami kısımlan silindir şekillidir ve sırasıyla, $8-10 \mu \mathrm{m}$ x 2,53 $\mu \mathrm{m}, 10-17 \mu \mathrm{m}$ x 3-4 $\mu \mathrm{m}$ ve $17-33 \mu \mathrm{m}$ x 3-4 $\mu \mathrm{m}$ boyutlarındadır (Frisvad ve Samson, 2004; Visagie vd., 2014).

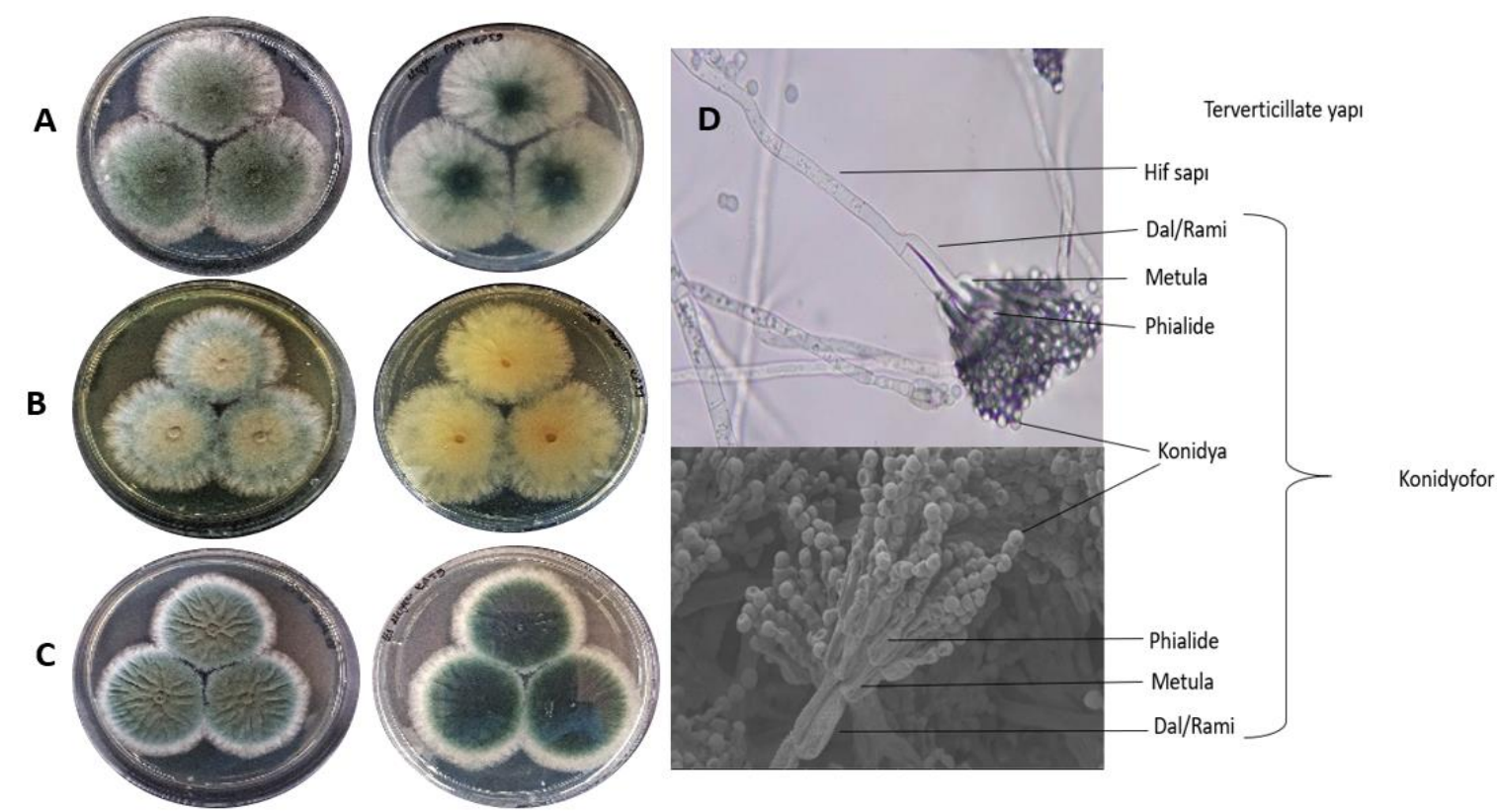

Şekil 1. Bir Penicillium roqueforti suşunun farklı besiyerlerinde, sırasıyla, PDA'da ön-arka (A), MEA'da önarka (B), YES'de ön-arka (C) koloni morfolojileri ve mikroskobik hif yapıs1 (D) (Kırtıl, 2018; Seri, 2020)

\section{P. ROQUEFORTPNIN TAKSONOMISİ VE GENETİ̆̆İ}

Penicillium roqueforti türü, Penicillium cinsinin Roquefortorum (Roqueforti) serisinde siniflandirilir. Bu seride filogenetik olarak birbirine yakın türler, $P$. roqueforti, $P$. carneum, $P$. paneum, $P$. psychrosexualis ve $P$. mediterraneum ile yer almaktadır (Houbraken vd., 2010; Guevara-Suarez vd., 2020). Funguslar için genetik tanımlamada kullanılan üniversal gen bölgelerinden 18S rRNA ve 28S (D1/D2) rRNA, bu türleri tam olarak ayıramamaktadır. Bu türlerin tanımlanmasinda ve sinıflandirlmasinda, ITS, $\beta$ tubulin (tub2, ben $A)$, calmodulin $(c m d A)$ ve RNA polimeraz II geni alt birimi ( $(p b 2)$ gen bölgeleriyle çoklu bölge dizi tiplemesi (MLST) analizi son yıllarda sıklıkla kullanılmaktadır (Houbraken vd., 2010; Houbraken vd., 2016; Guevara-Suarez vd., 2020). Özellikle, Roquefortorum serisinin $\beta$-tubulin dizilimlerinin polimorfizm gösterdiği bildirilmiştir (Houbraken vd., 2010). Roquefortorum serisi üyelerinin $\beta$-tubulin dizilimleri kullanilarak elde edilen filogenetik ağaç, türlerin ayrımını açıça göstermektedir (Şekil 2). Bu ağaca göre, $P$. roqueforti’ye en yakın türün $P$. mediterraneum olduğu görülmektedir. Otçul hayvan gübrelerinden izole edilmiş olan P. mediterraneum, Roquefortorum serisine yeni dahil edilmiştir. Bu türün, $P$. roqueforti ile ITS dizilimi aynı iken, tub2, $c m d A, r p b 2$ dizilimlerinde farklılıkların olduğu ifade edilmiştir (GuevaraSuarez vd., 2020).

P. roqueforti suşlarının da kendi içinde çeşitlilik gösterdiği bildirilmiştir. Gillot vd. (2015), P. roquefortinnin farklı morfolojilere sahip izolatları arasında 9 değişik morfolojik tipi olduğunu tespit etmişlerdir. Bu çalışmada çeşitli lokuslar polimorfizm açısından incelenmiş; çeşitlilik hakkında bilgi verici 8 lokus $(\beta$-tub, cmd, cct $8, t s r 1$, mom 7, Proq235, Proq631, Proq845) ve 4 mikrosatelit bölgesi (Proq16, Proq17, Proq01_3, Proq02_2) 
tespit edilmiştir. $P$. roqueforti izolatlarının bu polimorfik bölgeler kullanılarak birbirlerine yakınlıklarına göre gruplara ayrilması sonucunda, değişik peynir türlerinden elde edilen izolatlann değişik gruplara yerleştiği görülmüştür.

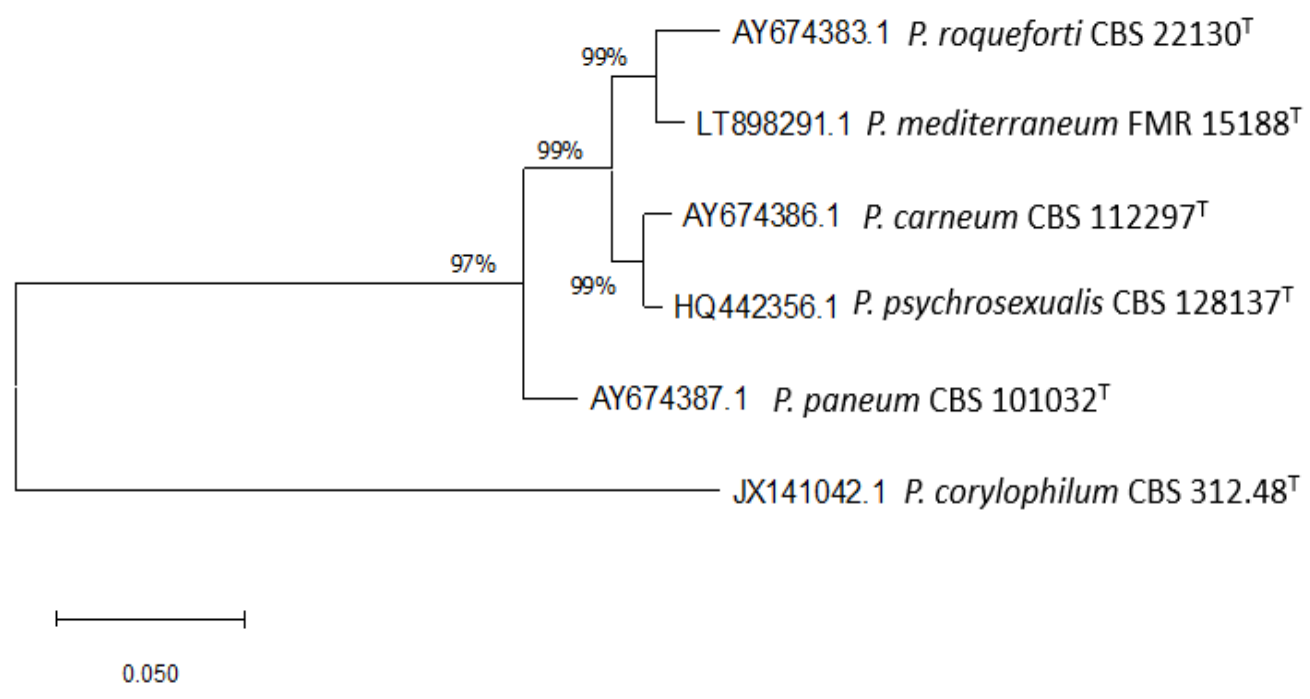

Şekil 2. Roquefortorum serisinin $\beta$-tubulin gen dizilimleri ve Maximum-likelihood metodu kullanilarak elde edilen filogenetik ilişkisi. Kullanılan tip ( ${ }^{\mathrm{T}}$ ) suşlar: Penicillium roqueforti CBS 221.30 ${ }^{\mathrm{T}}$ (AY674383.1), Penicillium mediterraneum FMR 15188'T (LT898291.1), Penicillium carneum CBS 112297T (AY674386.1), Penicillium psychrosexualis CBS 128137T (HQ442356.1) ve Penicillium paneum CBS 101032T (AY674387.1). Dizilimler Clustal W programı ile hizalanmış ve filogenetik ağaç, Mega X (Versiyon 10.1.1) programı kullanılarak oluşturulmuştur.

P. roquefortinin farklı morfolojilere sahip suşları, daha önce, kullanıldığı peynire özgü, teknolojik olarak P. glaucum, P. gorgonzolae, P. stilton şeklinde isimlendirilmiştir. Ancak, bu isimlendirme taksonomik geçerliliği olmadığı için kullanılmamıştır (Gillot vd., 2015). Son çalışmalarda, yüzyıllar boyunca farklı peynir üretim proseslerinin kullanılmasının $P$. roqueforti popülasyon yapısını şekillendirdiği öne sürülmüştür. Böylece, bu türün evrimleşme sürecine dair ipuçları sunulmuştur (Gibbons ve Rinker, 2015; Gillot vd., 2015; Ropars vd., 2016a; Ropars vd., 2016b; Bodinaku vd., 2019; Dumas vd., 2020). Farklı peynir türlerine ait izolatların kümelenmesiyle, $P$. roqueforti popülasyonunun yabani ortak bir atadan gelerek nasil evcilleştirildiğine, peynir ortamına nasıl adapte olduğuna ve genetik farklılıklarına dair ipuçları elde edilmiştir. Fungusların evcilleşmesi ve ortam adaptasyonunun, yatay gen transferi (HGT), tekrarlı indüklenmiş nokta (RIP) mutasyonları, seçici delesyon, hibridizasyon gibi mekanizmalar ve retrotranspozonlar, hareketli DNA elemanları gibi araçlar ile sağlanmış olabileceği ifade edilmiştir. Bunlar arasında HGT'nin gida zincirinde farklı örnekleri belirtilmiş olup, adaptasyon sürecinde ön plana çıkmıştır (Cheeseman vd., 2014; Dumas vd., 2020). P. roquefortinnin evcilleşme süreci, özellikle genomuna kazandırdığ 1 yatay gen transfer bölgelerinde (HGT) bulunan, laktoz metabolizması ve antimikrobiyal özellikleri içeren, CheesyTer ve Wallaby gen bölgeleriyle ilişkilendirilmiştir. Peynirin olgunlaşma sürecinin ilk günlerinde, bu bölgelerdeki genler yüksek oranda ifade edilerek $P$. roqueforti suşlarına, diğer türlere karşı peynir ortamında yanışmacı ve hızlı gelişme özelliklerini kazandırmaktadır (Cheeseman vd., 2014; Ropars vd., 2015; Dumas vd., 2020). Ayrica bu bölgeler vasitasiyla $P$. roqueforti peynirin besin kaynaklarını kullanabilme, proteoliz ve lipoliz mekanizmaları, tuzlu ortamda gelişme, peynirin olgunlaşma 
sürecinin başında düşük $\mathrm{pH}$ değerini tolere etme, peynir oyuklarına kolonizasyon yeteneği gibi özellikler kazanmıştır (Ropars vd., 2012; Monnet vd., 2014). HGT bölgeleri, P. roqueforti FM164 suşunun tüm genomunun dizilenmesiyle, bu türde ilk defa tespit edilmiştir (Ropars vd., 2012; Cheeseman vd., 2014; Ropars vd., 2015). Wallaby bölgesi, 248 geni barındırdığından ve $575 \mathrm{~kb}$ boyutunda olduğundan uzun bir genomik ada olarak tanımlanmıştır. Bu bölgede bulunan paf ve hce2 genlerinin, $P$. roqueforti'nin diğer mikroorganizmalara karşı antagonistik özellikleri barındıran antifungal proteinleri kodladığ 1 ifade edilmiştir (Cheeseman vd., 2014; Ropars vd., 2015; 2016a). İkinci büyük bölge olan CheesyTer ${ }^{2}$ in, 37 gen bulundurduğu ve $80 \mathrm{~kb}$ uzunluğunda olduğu tespit edilmiştir. $\mathrm{Bu}$ bölge, laktoz metabolizmasindan sorumlu laktoz permeaz ve $\beta$ galaktosidaz mekanizmalarını kodlayan genleri barındirır (Ropars vd., 2015). Ayrıca, HGT bölgelerini bulunduran $P$. roqueforti suşlarının peynir aromasina da önemli katkıs1 bulunmaktadır. Lipoliz sonucu peynir ortamında lipid degradasyonunun artmasiyla, ketonlar ve uçucu bileşikler açığa çıkmaktadır. Bunlardan en önemlileri, küflü aroma yerine peynirimsi aromaların ortamda oluşmasını sağlayan 2heptanon, 8-nonen-2-on, 2-tridekanon gibi bileşiklerdir (Bodinaku vd., 2019; Dumas vd., 2020). Gürkan vd. (2018), Erzurum Civil peynirlerinde çoğunlukla ketonlardan ve alkollerden oluşan 65 uçucu bileşik tespit etmiş ve bu bileşiklerden 2-nonanon, 3-metil-2-pentanon, 2-bütanon ve 2-pentanon ön plana çıkmıştır. Ayrıca bu bileşikler ve oranları, peynirin olgunlaşma sıcaklı̆̆1 ve süresine göre değişmiştir.

P. roqueforti pek çok ekolojik ortamda bulunabilir. $\mathrm{Bu}$ türün, Rokfor peyniri ve diğer peynirlerden izole edilen suşlarının yanı sıra, ağaçlık alan, silaj ya da gıda kontaminantı olarak peynir dışı ortamdan izole edilen suşları olarak toplam 4 popülasyonu belirlenmiștir (Gillot vd., 2015; Coton vd., 2020; Dumas vd., 2020) (Çizelge 1). Bu popülasyonlar, koloni yapısı ve rengi, gelişme hızı, sporlanma oranı ve hızı gibi fenotipik farklılıklar göstermektedir. Popülasyon 4, Wallaby ve
CheesyTer genlerini bulundurmaktadır. Ayrıca bu popülasyonda, mikofenolik asit üretiminde anahtar gen olan mpaCde 174 bp'lik bir delesyon nedeniyle, bu toksinin üretimi çok düşük düzeyde olmakta ya da yapilamamaktadir (Gillot vd., 2017b; Coton vd., 2020). Rokfor peynirinden izole edilen Popülasyon 3'te, Popülasyon 1 ve Popülasyon 2'de olduğu gibi HGT bölgeleri bulunmamakta ve $m p a C$ geni bulunmaktadır. Bu popülasyonun farklı bir kaynaktan gelerek (silaj ortamından vb.) mağara ortamından peynire yerleşmiş olabileceği öne sürülmüştür (Ropars vd., 2017; Dumas vd., 2020).

Son çalışmalar, $P$. roquefortìnin eşeyli üreme yapabildiğini ortaya koymuştur (Ropars vd., 2014; 2016b). Ascomycetes'lerden P. roquefortin nin farkli popülasyonlarının haploid genomlarının MAT1-1 ya da MAT1-2 olmak üzere, insandaki $\mathrm{X}$ ve $\mathrm{Y}$ kromozomlarına benzer şekilde, tek bir eşey tipi lokusu taşıdığ1 bildirilmiştir (Ropars vd., 2016a). $\mathrm{Bu}$ lokus, feromonlar ve feromon reseptörlerinin üretimini indükleyen transkripsiyon faktörlerini kodlar (Lopez-Villavicencio vd., 2010). Ropars vd. (2014), P. roqueforti suşlarının biyotin ilave edilmiş Oat Meal Agar (OA)'da eşeyli üreme özelliklerini incelemiştir. Suşların besince zengin ve stabil koşullarda değil de zorlu koşullarda eşeyli üreme yapabildiği bildirilmiştir. Evrimsel süreçte, eşeyli üreme genlerinin $P$. roqueforti’ de yüksek oranda korunmuş olduğu ifade edilmiştir. Ayrıca, peynirden izole edilen popülasyonun \%91'inin MAT1-2 eşey tipine sahip olduğu tespit edilmiştir. MAT1-1 eşey tipi, daha çok diğer $P$. roqueforti popülasyonlarında (\%82) tespit edilmiştir (Ropars vd., 2014). Deneysel çalışmalar, eşeyli üremenin eşeysiz üremeye göre zararlı mutasyonları azalttı̆̆ını ortaya koymuştur (Ropars vd., 2012). Eşeyli üremenin biyoteknolojik açıdan da önemi söz konusudur. Peynir üretiminde çeşitliliği sağlayacak farklı fenotiplere sahip yeni genotipler kolaylıkla geliştirilebilir veya rekombine edilebilir. Yeni nesil suşlar, eşleşen atalarının her ikisinden de gen alarak yeni özellikler kazanabilir ve değişken çevre koşullarına dayanıklı hale gelebilir (Ropars vd., 2012; 2014). 
Çizelge 1. P. roqueforti popülasyonlan ve özellikleri (Coton vd., 2020)

\begin{tabular}{|c|c|c|c|c|c|}
\hline \multirow{2}{*}{ Popülasyon Türü } & \multirow{2}{*}{ İzolasyon Kaynağ1 } & \multicolumn{2}{|c|}{ HGS Bölgeleri } & \multicolumn{2}{|c|}{ Metabolitler } \\
\hline & & Wallaby & CheesyTer & $m p a C$ Geni & Metabolitler \\
\hline Popülasyon 1 & $\begin{array}{l}\text { Ağaçlık alan, } \\
\text { Gıda kontaminant }\end{array}$ & Yok & Yok & Var & zzla \\
\hline Popülasyon 2 & $\begin{array}{l}\text { Silaj, } \\
\text { G1da kontaminant }\end{array}$ & Yok & Yok & Var & $\begin{array}{c}\text { metabolit ve } \\
\text { 65'ten fazla uçucu }\end{array}$ \\
\hline Popülasyon 3 & Rokfor peyniri & Yok & Yok & Var & bileşik** üretimi \\
\hline Popülasyon 4 & Diğer peynirler & Var & Var & Delesyon* & \\
\hline
\end{tabular}

* mpaC geni delesyona uğradığından mikofenolik asit üretimi çok düşük/yok düzeyde.

**Popülasyon 3’teki suşlar, uçucu bileşik çeşitliliğine sahipken; Popülasyon 4, düşük çeşitliliğe sahip.

Son çalışmalar, $P$. roqueforti’nin eşeyli üreme yapabildiğini ortaya koymuştur (Ropars vd., 2014; 2016b). Ascomycetes'lerden P. roquefortinin farkl1 popülasyonlarının haploid genomlarının $M A T 1-1$ ya da MAT1-2 olmak üzere, insandaki X ve Y kromozomlarına benzer şekilde, tek bir eşey tipi lokusu taşıdığı bildirilmiştir (Ropars vd., 2016a). $\mathrm{Bu}$ lokus, feromonlar ve feromon reseptörlerinin üretimini indükleyen transkripsiyon faktörlerini kodlar (Lopez-Villavicencio vd., 2010). Ropars vd. (2014), P. roqueforti suşlarının biyotin ilave edilmiş Oat Meal Agar (OA)'da eşeyli üreme özelliklerini incelemiştir. Suşların besince zengin ve stabil koşullarda değil de zorlu koşullarda eşeyli üreme yapabildiği bildirilmiştir. Evrimsel süreçte, eşeyli üreme genlerinin $P$. roquefortide yüksek oranda korunmuş olduğu ifade edilmiştir. Ayrıca, peynirden izole edilen popülasyonun \%91'inin MAT1-2 eşey tipine sahip olduğu tespit edilmiştir. MAT1-1 eşey tipi, daha çok diğer $P$. roqueforti popülasyonlarında (\%82) tespit edilmiştir (Ropars vd., 2014). Deneysel çalışmalar, eşeyli üremenin eşeysiz üremeye göre zararlı mutasyonları azalttığını ortaya koymaktadır (Ropars vd., 2012). Eşeyli üremenin biyoteknolojik açıdan da önemi söz konusudur. Peynir üretiminde çeşitliliği sağlayacak farklı fenotiplere sahip yeni genotipler kolaylıkla geliştirilebilir veya rekombine edilebilir. Yeni nesil suşlar, eşleşen atalarının her ikisinden de gen alarak yeni özellikler kazanabilir ve değişken çevre koşullarına dayanıklı hale gelebilir (Ropars vd., 2012; 2014).

\section{P. ROQUEFORTTNİN FİZYOLOJİSİ VE METABOLİZMASI}

$P$. roqueforti'nin optimum inkübasyon şartlan, aerobik ortam ve $25^{\circ} \mathrm{C}$ 'de 5-7 gündür. Ayrica, propiyonik aside, asetik aside, laktik aside, yüksek konsantrasyonda $\mathrm{CO}_{2}$ 'ye ve $\% 5$ 'e kadar $\mathrm{NaCl}^{\prime} y e$ tolerans göstermektedir. Ayrıca, peynirin olgunlaşması sırasında, depo koşullarındaki (10$12^{\circ} \mathrm{C}$ ) sıcaklıklarda gelişebilir ve daha düşük sicaklıklara da dayanıklıdır (Frisvad ve Samson, 2004; Visagie vd., 2014; Gillot vd., 2015). Bu tür, peynirdeki metabolik süreçler sonucu primer ve sekonder metabolitler üretebilir. Primer metabolitler, yaşamsal faaliyetler sonucu oluşan temel metabolizma ürünleridir. Peynirden izole edilen pek çok $P$. roqueforti suşu, karbonhidrat metabolizmasinda laktoz permeaz ve $\beta$ galaktosidaz enzimlerini bulundurduğundan laktozu kullanabilir (Ropars vd., 2015). Proteolitik ve lipolitik aktiviteler sonucu bazı biyoaktif peptidler ve uçucu aromatik bileşikler (2heptanon, 8-nonen-2-on, 2-tridekanon vb.) üretebilir. $P$. roqueforti, melanin biyosentezi gen kümesini bulundurduğundan mavi-damarlı, küfle olgunlaştrrlan peynirlere has mavi-yeşil renkleri oluşturan pigmentleri üretir. Bu pigmentlerin spor yüzeyini kaplayan melanini oluşturduğu bildirilmiştir (Cleere, 2017; Bodinaku vd., 2019; Coton vd., 2020). Daha önce Aspergillus fumigatus'ta bulunan $\mathrm{DHN}$-melanin biyosentez yolu, $P$. roqueforti' de de tespit edilmiştir. DHNmelanin biyosentezi gen kümesi, 6 gen içerir ve 19 kb büyüklügündedir. Bu gen kümesinde bulunan genlerin UV mutajenez yöntemi kullanılarak kahverengi, pembe, yeşil, koyu mavi, beyaz renkli sporlar üretilebildiği ifade edilmiştir. Böylece, mutant sporlar kullanılarak değişik renkte peynirler üretilebilir ve peynir endüstrisine ilgi çekici bir pazarlama stratejisi olarak sunulabilir (Cleere, 2017). 
Sekonder metabolitler, genellikle yaşamsal faaliyetleri sürdürmek için gerekli olmayan, mikotoksinleri ve bazı biyoaktif bileşikleri içerirler. Bazıları tubbi uygulamalarda ve farmakolojide kullanılırken, bazıları da insan sağlı̆̆ına zararlıdır. Mikotoksinler, sağlık problemlerine (kanserojen, teratojen, mutajen etkiler vb.) neden olmalarının yanı sıra ekonomik zararlara da yol açabilirler (Şengün vd., 2008; Hymery vd., 2014). Sekonder metabolitler genel olarak, yapı bloklarından; özellikle terpen sentaz, poliketid sentaz, ribozomal sentaz ve ribozomal olmayan peptid sentaz enzim gruplarının aktiviteleriyle sentezlenir. Biyosentezi sağlayan enzimleri kodlayan genler, bir gen kümesinde birbirine bağlı olarak bulunur (Brown vd., 2011). Son yillarda, $P$. roqueforti'nin sekonder metabolitlerinin gen kümeleri ve fonksiyonları belirlenmiştir. Bu metabolitler arasında rokfortin C, mikofenolik asit, PR toksin, izofumigaklavin gibi bileşikler mikotoksin olarak değerlendirilirken, andrastin A biyoaktif bir bileşik olarak ön plana çıkmaktadır (Hymery vd., 2014; Garcia-Estrada ve Martin, 2016). Rokfortin C, Gram pozitif bakterilere karşı antibakteriyal aktiviteye sahiptir. Ayrıca, bu mikotoksinin düşük seviyede de olsa nörotoksik ve sitotoksik etkileri bildirilmiştir (Kosalkova vd., 2015; GarciaEstrada ve Martin, 2016). Mikofenolik asit, böbrek, karaciğger, kalp nakli yapılan hastalarda organ reddini önlemek için kullanılan immünosupresif bir bileşik olarak ilaçların formülasyonlarında kullanılır (Del-Cid vd., 2016; Gillot vd., 2017b). Andrastin A ise, antitümör ve antikarsinojen etkileri tespit edilmiş biyoaktif bir bileşiktir ve $P$. roqueforti tarafindan peynir ortamında üretimi saptanmıştır (FernandezBodega vd., 2009).

Mikotoksin üretiminde biyotik faktörlerin yanı sıra $\mathrm{pH}$, sicaklık, $\mathrm{NaCl}$ ve $\mathrm{O}_{2}$ içeriği, $\mathrm{C} / \mathrm{N}$ oranı gibi abiyotik faktörlerin de önemli olduğu bilinmektedir (Fontaine vd., 2015). Ayrica, çevresel faktörlerin yanı sıra substrat yapısı da önemlidir. Her gida maddesinde benzer şekilde ortaya çımamaktadır. P. roqueforti'nin bazı suşları peynirde PR toksin, rokfortin, mikofenolik asit, isofumigaklavin üretebilir. Ancak, peynirin aminoasit kompozisyonu ve mikroaerofilik koşullar nedeniyle, PR toksin peynirde kararlı değildir ve peynir ortamında toksisitesi daha düşük olan PR imine indirgenir (Hymery vd., 2014; Perrone ve Susca, 2017). Mikotoksin üretimi daha çok Çizelge 1'deki ağaçlık alan, silaj gibi izolasyon kaynakları olan ve gidalarda bozulmaya yol açan Popülasyon 1 ve Popülasyon 2 ile ilişkilendirilebilir. Ayrıca bulgular, $P$. roquefortinin evrimsel süreçte peynire adaptasyonunda bazı sekonder metabolitlerinin üretimini azalttı̆̆ını göstermektedir. Örneğin, Çizelge 1'deki Popülasyon 4'teki suşlar mikofenolik asit üretiminde anahtar gen olan mpaCde 174 bp'lik bir delesyon bulundurduğundan, bu toksinin üretimi çok düşük düzeydedir ya da yapılamamaktadır (Gillot vd., 2017b; Coton vd., 2020). Bu popülasyondaki Wallaby ve CheesyTer HGT bölgelerine sahip suşlar peynirde gelişerek, diğer mikotoksijenik türlerin gelişmesini baskılayabilir. Ayrıca, Roquefortorum serisine ait diğer türlerden $P$. paneum, $P$. carneum ve P. psychrosexualis'in patulin üretimi söz konusudur (Hymery vd., 2014; Perrone ve Susca, 2017). P. mediterraneum in ikincil metabolitleriyle ilgili bir bilgi literatürde henüz yer almamaktadır.

\section{BİYOTEKNOLOJIK POTANSİYEL VE STARTER KÜLTÜR OLARAK $P$. ROQUEFORTPNIN KULLANIMI}

$P$. roqueforti, sekonder starter kültür olarak mavidamarlı ve diğer küflü peynirlerin olgunlaştrrılmasında kullanılır. Bu kültür, liyofilize sporlar formunda süt içine katllır veya peynir pihtısı üzerine spor solüsyonu halinde püskürtülerek bulaştırilır. Ticari starter kullanılmayan, geleneksel yöntemlerle üretimlerde ise ortamdan bulaşarak peynirde spontan olarak gelişebilir. Böylece olgunlaşma süreci sonunda küflü peynirlere has tat, koku ve aroma oluşur (Fox vd., 2016b; Metin, 2018).

Peynir endüstrisinde, $P$. roqueforti sporlar1 klonal suştan geliştirilir ve böylece suşlar eşeysiz üreme ile çoğaltılır. $P$. roqueforti’nin biyoteknolojik izolatları arasında, bir türün tek klonunu temsil ettiğinden genomlarında herhangi bir polimorfizm bulunmaz. $\mathrm{Bu}$ nedenle yeni suş geliştirilmesi, çoğunlukla rastgele mutasyona bağlıdır. Eşeyli üreme ile aynı atadan gelen farklı 
bireyler, yeni nesil suşlarda genetik çeşitliliği, rekombinasyonu sağlar ve zararlı mutasyonlar genomdan temizlenebilir (Giraud vd., 2010; Ropars vd., 2012; 2014). Eşeyli üreme, endüstriyel suşların geliştirilmesinde kullanılabilecek kolay bir yöntemdir (Böhm vd., 2013). Bu yöntemle geliştirilen suşlara istenen özellikler kazandırılabilir ve yeni çeşit peynirler üretilebilir. Ayrıca, evcilleşen popülasyonun peynir üretimi prosesinde stabil kalması sağlanabilir ve güvenilir, yüksek kalitede peynir üretimi yapılabilir (Bodinaku vd., 2019). Geleneksel peynirlerin kendilerine has dokusu da korunabilir.

Yatay gen transferi ile hareketli DNA elemanlarının ökaryotik genomlara girişi, temel genomik çeşitlilik ve biyoteknolojik inovasyon için önemli bir itici güç olmuştur. Evrimsel süreçte, genetik modifikasyonun organizmaların sadece atalarına değil ekolojilerine de bağlı olduğu tespit edilmiş ama tüm mekanizmalar henüz açıklanamamıştır (Schaack vd., 2010). P. roqueforti nin evrimsel sürecinin ve peynir ortamına adaptasyon mekanizmalarının aydınlatılması ile HGT genleri gibi birçok aday alternatif genin tanımlanması sağlanabilir. Böylelikle, peynir üretimi için ilginç özellikler seçilerek yeni nesil starterler üretilebilir (Dumas vd., 2020).

P. roqueforti, katma değeri yüksek molekülleri üretebildiği için multifonksiyonel hücre fabrikası olarak nitelendirilmiştir (Mioso vd., 2015). Proteolitik-lipolitik aktiviteleri nedeniyle enzimatik potansiyeli bilinmektedir. Ayrıca, medikal uygulamalar için metabolit üretiminde, gıda uygulamaları için aroma üretiminde ve biyoremediasyon ajanı olarak kullanılabilir (Coton vd., 2020).

\section{PEYNİRIN OLGUNLAŞMA SÜRECİNDE P. ROQUEFORTPNIN ROLÜ}

Peynirlerde sekonder starter olarak kullanilan $P$. roqueforti, peynirin olgunlaşma sürecinde bakterilerle ve mayalarla etkileşim halindedir. Starter kültür olarak özellikle laktik asit bakterilerinin (Lactobacillus spp., Lactococcus spp.) yanı sıra peynir çeşidine ve üretim metoduna göre Brevibacterium linens, Propionibacterium spp. gibi bakteriler ve Debaryomyces spp., Kluyveromyces spp., diğer Penicillium spp., Geotrichum candidum gibi fungal türler ortamda bulunabilir (Anonim, 2015; Fox vd., 2016c; Metin, 2018). Ancak, özellikle Çizelge 1'de verilen Popülasyon 4'e dahil olan suşlar, HGT genleri bulundurduğundan diğer fungal türlerin peynir ortamında gelişimini baskılayabilir. Avrupa tipi mavi-damarlı peynirlerde ve ülkemizde üretilen Erzurum Küflü Civil, Konya Küflü, Divle Obruk Tulum gibi peynirlerde yapılan çalışmalarda $P$. roqueforti, peynir mikrobiyotasında dominant tür olarak tespit edilmiştir (Çakmakçı vd., 2012; Öztürkoğlu Budak, 2016; Kırtll, 2018; Seri, 2020).

P. roqueforti başta olmak üzere, küflerin metabolik aktiviteleri sonucu farklı aroma maddeleri ve metabolitler oluşmaktadır. Ayrıca küfler, peynir tekstüründe önemli değişikliklere neden olmaktadır. Olgunlaşma sürecinde, küflerin neden olduğu biyokimyasal reaksiyonlar sonucu, küflü peynirlere has koku, aroma ve tat oluşur. $\mathrm{Bu}$ reaksiyonlar temel olarak, deasidifikasyon, proteolitik ve lipolitik aktiviteler olarak sinıflandirilabilir (Fox vd., 2016d). Ayrica, peynirde mavi-yeşil rengi sağlayan küf pigmentleri üretimi ve sekonder metabolit üretimi de gerçekleşir (Cleere, 2017; Coton vd., 2020).

Deasidifikasyon sonucu $P$. roqueforti, laktik asit bakterilerinin ürettiği laktik asidi karbon kaynağ1 olarak kullanır. Pıhtı asitliğini nötralize ederek ortam pH'sını 4,5'tan 7'ye doğru yükseltir. Bu tür ayrica, endopeptidaz ve ekzopeptidaz aktivitesine sahip olduğundan kazeini hidrolize edebilir. Böylece peynir matriksinde serbest aminoasitler oluşur. Serbest aminoasitler, amonyak ve uçucu bileşiklere parçalanarak olgunlaşmayı hızlandırır. Lipolitik aktiviteler sonucu ise, küflü peynirlerin karakteristik aroması oluşur. Serbest yağ asitlerinden metil ketonlar ve onlarnn sekonder alkolleri meydana gelir (Fox vd., 2016d; Martin ve Coton, 2017; Bodinaku vd., 2019).

\section{SONUÇ}

Mavi-damarlı peynirler gibi küflü peynirlerin olgunlaştrilmasında sekonder starter olarak kullanilan $P$. roqueforti, son yillarda gida kaynaklı küfler arasinda en çok incelenen tür olarak ön plana çıkmaktadır. Küflü peynirlere has tat, aroma 
ve kokuyu oluşturan bu türün incelenmesi, g1da sanayi açısından oldukça önemlidir. $P$. roquefortinin evcilleşme ve adaptasyon süreci üzerine son çalışmalar, bu türün popülasyonlarını ve özelliklerini belirleyerek filogenetik pozisyonunu yeniden şekillendirmiştir. $P$. roqueforti nin evcilleşme sürecinin araştırilmasıyla ve henüz bilinmeyen sekonder metabolit gen kümelerinin tespit edilmesiyle, bu türün fizyolojisi ve metabolizması daha iyi anlaşılabilir. Bu türün popülasyonlarının tüm genomlarının dizilenmesi, metabolik potansiyeli ve regülasyonu için yeni ipuçları sunacaktır. Bu derlemede, peynir küfü olarak $P$. roquefortinin morfolojisi, genetik özellikleri, taksonomisi, fizyolojisi ve metabolitleri, peynirin olgunlaşma rolü incelenerek özetlenmiş, peynir ortamına adaptasyon ve evcilleşme süreci ile ilgili elde edilen yeni bulgular değerlendirilmiştir. Ayrıca, $P$. roquefortinin eşeyli üreme kabiliyetine de değinilmiştir. Eşeyli üreme ile farklı bireylerin özelliklerinin rekombinasyonuyla farklı fenotiplere sahip yeni nesiller geliştirilebilir. Bu durum, starter kültür geliştirilmesi açısından biyoteknolojik önem arz etmektedir.

\section{TEŞEKKÜR}

Bu çalışma, 119 O314 numaralı TÜBİTAK projesi tarafından desteklenmiştir.

\section{ÇIKAR ÇATIŞMASI}

$\mathrm{Bu}$ makale ile ilgili olarak başka kişiler ve/veya kurumlar arasında bir çıkar çatışması yoktur.

\section{YAZAR KATKILARI}

HEK ve BM derleme çalışmasını planlamış, HEK makale taslağını hazırlamıs, $B M$ ve MA inceleme ve düzenleme aşamalarında katkı sağlamışlardır. Tüm yazarlar makalenin son halini okumuş ve onaylamışlardır.

\section{KAYNAKLAR}

Anonim, (2015). "Geotrichum candidum", http://microbialfoods.org/geotrichum-

candidum-mold-transition/ , Son Erişim tarihi: 14.07.2020

Bodinaku, I., Shaffer, J., Connors, A.B., Steenwyk, J.L., Biango-Daniels, M.N., Kastman, E.K., Rokas, A., Robbat, A., Wolfe, B.E. (2019).
Rapid phenotypic and metabolomic domestication of wild penicillium molds on cheese. ASM MBio, 10(5): e02445-19. https://doi.org/10.1101/647172

Böhm, J., Hoff, B., O’Gorman, C.M., Wolfers, S., Klix, V., Binger, D., et al. (2013). Sexual reproduction and mating-type-mediated strain development in the penicillin-producing fungus Penicillium chrysogenum. Proc Natl Acad Sci USA, 110(4): 1476-1481. https://doi.org/10.1073/pnas.1217943110

Brown, D.W., Butchko, R.A.E., Proctor, R.H., (2011). Identification of genes and gene clusters involved in mycotoxin synthesis. Ed.: De Saeger, S., Woodhead Publishing, 2nd edition, Cambridge, UK, 333-348 p.

Cleere, M., (2017). Pigment Biosynthesis Genes in the Blue Cheese Fungus Penicillium roqueforti, $\mathrm{PhD}$ thesis, University of Nottingham, Nottingham, UK, 93 p.

Cheeseman, K., Ropars, J., Renault, P., Dupont, J., Gouzy, J., Branca, A., Abraham, A.L., Ceppi, M., Conseiller, E., Debuchy, R., Malagnac, F., Goarin, A., Silar, P., Lacoste, S., Sallet, E., Bensimon, A., Giraud, T., Brygoo, Y., (2014). Multiple recent horizontal transfers of a large genomic region in cheese making fungi. Nature Communications, 2876. https://doi.org/10.1038/ncomms3876

Coton, E., Coton, M., Hymery, N., Mounier, J., Jany, J.J., (2020). Penicillium roqueforti: an overview of its genetics, physiology, metabolism and biotechnological applications. Fungal Biol Rev, 34(2): 59-73.

https://doi.org/10.1016/j.fbr.2020.03.001

Çakmakçı, S., (2011). Türkiye Peynirleri. Peynir Biliminin Temelleri, Ed.: Hayaloğlu, A.A. ve Özer, B., 1.Bask1, Sidas Medya Ltd. Şti., İzmir.

Çakmakçı, S., Çetin, B., Gürses, M., Dağdemir, E., Hayaloğlu, A.A., (2012). Morphological, molecular and mycotoxigenic identification of dominant filamentous fungi from Moldy Civil Cheese. J Food Prot, 75 (11): 2045-2049. https://doi.org/10.4315/0362-028X.JFP-12-107 
Del-Cid, A., Gil-Duran, C., Vaca, I., Rojas-Aedo, J.F., Garcia-Rico, R.O., Levican, G., Chavez, R., (2016). Identification and functional analysis of the mycophenolic acid gene cluster of Penicillium roqueforti. PLoS One, 11(1): e0147047. https://doi.org/10.1371/journal.pone.0147047

Dumas, E., Feurtey, A., Rodríguez de la Vega, R.C., Le Prieur, S., Snirc, A., Coton, M., Thierry, A., Coton, E., Le Piver, M., Roueyre, D., Ropars, J., Branca, A., Giraud, T. (2020). Independent domestication events in the blue-cheese fungus Penicillium roqueforti. Molecular Ecology, 00: 1- 22. https://doi.org/10.1101/451773

Fernandez-Bodega, M.A., Mauriz, E., Gomez, A., Martin, J.F., (2009). Proteolytic activity, mycotoxins and andrastin A in Penicillium roqueforti strains isolated from Cabrales, Valdeon and BejesTresviso local varieties of blue-veined cheeses. Int $J$ of Food Microbiol, 136(1): 18-25. https://doi.org/10.1016/j.ijfoodmicro.2009.09.0 14

Frisvad, C.F., Samson, R.A., (2004). Polyphasic taxonomy of Penicillium subgenus Penicillium: A guide to identification of food and air-borne terverticillate Penicillia and their mycotoxins. Stud Mycol, 49: 1-174.

Fox, P.F., Guinee, T.P., Cogan, T.M., McSweeney, P.L.H., (2016a). Principal families of cheeses: Blue veined cheeses (Chapter 3). In: Fundamentals of Cheese Science, 2rd edition, Springer, New York, pp. 54-57.

Fox, P.F., Guinee, T.P., Cogan, T.M., McSweeney, P.L.H., (2016b). Cheese Flavour (Chapter 13). In: Fundamentals of Cheese Science, 2rd edition, Springer, New York, pp. 443-472.

Fox, P.F., Guinee, T.P., Cogan, T.M., McSweeney, P.L.H., (2016c). Microbiology of Cheese Ripening (Chapter 11). In: Fundamentals of Cheese Science, 2rd edition, Springer, New York, pp. 333-351.

Fox, P.F., Guinee, T.P., Cogan, T.M., McSweeney, P.L.H., (2016d). Biochemistry of Cheese Ripening (Chapter 12). In: Fundamentals of Cheese Science, 2rd edition, Springer, New York, pp. 391-439.
Fontaine, K., Hymery, N., Lacroix, M.Z., Puel, S., Puel, O., Rigalma, K., Gaydou, V., Coton, E., Mounier, J., (2015). Influence of intraspesific variability and abiotic factors mycotoxin production in Penicillium roqueforti. Int $J$ of Food Microbiol, 215: 187-193. https://doi.org/10.1016/j.ijfoodmicro.2015.07.0 21

Garcia-Estrada, C., Martin, J.F., (2016). Biosynthetic gene clusters for relevant secondary metabolites produced by Penicillium roqueforti in blue cheeses. Appl Microbiol Biotechnol, 100: 83038313. https://doi.org/10.1007/s00253-0167788-x

Geisen, R., Cantor, M.D., Hansen, T.K., Holzapfel, W.H., Jakobsen, M., (2001). Characterization of Penicillium roqueforti strains used as cheese starter cultures by RAPD typing. Int $J$ of Food Microbiol, 65(3): 183-191. https://doi.org/10.1016/s0168-1605(00)00514-6

Gibbons, J.G., Rinker, D.C., (2015). The genomics of microbial domestication in the fermented food environment. Curr Opin Genet Dev, 35: 1-8. https://doi.org/10.1016/j.gde.2015.07.003

Gillot, G., Jany, J.L., Coton, M., Le Floch, G., Debaets, S., Ropars, J., Lopez- Villavicencio, M., Dupont, J., Branca, A., Giraud, T., Coton, E., (2015). Insights into Penicillium roqueforti: Morphological and genetic diversity. PLoS One, 10(6): $\quad$ e0129849 (1-21). https://doi.org/10.1371/journal.pone.0129849

Gillot, G., Jany, J.C., Poirier, E., Maillard, M.B., Debaets, S., Thierry, A., Coton, E., Coton, M., (2017a). Functional diversity within the Penicillium roqueforti species. Int J of Food Microbiol, 241: 141150.

https://doi.org/10.1016/j.ijfoodmicro.2016.10.0 01

Gillot, G., Jany, J.L., Dominguez-Santos, R., Poirier, E., Debaets, S., Hidalgo, P.I., Ullan, R.V., Coton, E., Coton, M. (2017b). Genetic basis for mycophenolic acid production and straindependent production variability in Penicillium roqueforti. Food Microbiol, 62: 239-250. https://doi.org/10.1016/j.fm.2016.10.013 
Giraud, F., Giraud, T., Aguileta, G., Fournier, E., Samson, R., Cruaud, C., Dupont, J. (2010). Microsatellite loci to recognize species for the cheese starter and contaminating strains associated with cheese manufacturing. Int $J$ of Food Microbiol, $137 \quad$ (2-3): $\quad$ 204-213. https://doi.org/10.1016/j.ijfoodmicro.2009.11.0 14

Guevara-Suarez, M., García, D., Cano-Lira, J.F., Guarro, J., Gené, J. (2020). Species diversity in Penicillium and Talaromyces from herbivore dung, and the proposal of two new genera of penicillium-like fungi in Aspergillaceae. Fungal Syst Evol, 5: 39-75. https://doi.org/10.3114/fuse.2020.05.03

Gürkan, H., Yılmaztekin, M., Çakmakçı, S., Hayaloğlu, A., (2018). Volatile compounds and biogenic amines during the ripening of moldripened Civil cheese manufactured using three different strains of Penicillium roqueforti. J Food Saf, 38e12568. https://doi.org/10.1111/jfs.12568

Houbraken, J., Frisvad, J.C., Samson, R.A., (2010). Sex in Penicillium series Roqueforti. IMA Fungus, $\quad 1(2)$ : 171-180. https://doi.org/10.5598/imafungus.2010.01.02. 10

Hymery, N., Vasseur, V., Coton, M., Mounier, J., Jany, J.L., Barbier, G., Coton, E., (2014). Filamentous fungi and mycotoxins in cheese: A review. Compr Rev Food Sci Food Saf, 13(4): 437456. https://doi.org/10.1111/1541-4337.12069

Kırtıl, H.E. (2018). Küflü peynirlerden izole edilen küflerin moleküler tanımlanması ve karakterizasyonu. Yıldız Teknik Üniversitesi, Fen Bilimleri Enstitüsü, Gıda Mühendisliği Anabilim Dalı, Yüksek lisans tezi, İstanbul, $131 \mathrm{~s}$.

Kosalkova, K., Dominguez-Santos, R., Coton, M., Coton, E., Garcia-Estrada, C., Liras, P., Martin, J.F., (2015). A natural short pathway synthesizes roquefortine $\mathrm{C}$ but not meleagrin in three different Penicillium roqueforti strains. Appl Microbiol Biotechnol, 99: 7601-7612. https://doi.org/10.1007/s00253-015-6676-0

López-Villavicencio, M., Aguileta, G., Giraud, T., de Vienne, D.M., Lacoste, S., Couloux, A., Dupont, J. (2010). Sex in Penicillium: Combined phylogenetic and experimental approaches, Fungal Genet Biol, 47(8): 693-706. https://doi.org/10.1016/j.fgb.2010.05.002

Martin, J.F. and Coton M., (2017). Blue Cheese: Microbiota and Fungal Metabolites. In: Fermented Foods in Health and Disease Prevention, Ed.: Frias, J., Martinez-Villaluenga, C., Penas, E., 1.Bask1, Academic Press.

Metin, B., (2018). Filamentous Fungi in Cheese Production. In: Microbial Cultures and Ensymes in Dairy Technology, Ed.: Öztürkoğlu Budak, Ş., Akal, H.C. 1st edition, IGI Global.

Mioso, R., Toledo Marante, F., Herrera Bravo de Laguna, I., (2015). Penicillium roqueforti: a multifunctional cell factory of high value-added molecules. J Appl Microbiol, 118: $781 \mathrm{e} 791$. https://doi.org/10.1111/jam.12706

Monnet, C., Landaud, S. Bonnarme, P., Swennen, D. (2014). Growth and adaptation of microorganisms on the cheese surface. FEMS Microbiol Lett, 362: 1-9. https://doi.org/10.1093/ femsle/ fnu025

MycoBank, (2020). Taxa descriptions: Penicillium roqueforti Thom, http://www.mycobank.org/BioloMICS.aspx?Ta bleKey $=14682616000000063 \&$ Rec $=15208 \&$ Fiel $\mathrm{ds}=$ All, Son Erişim Tarihi: 3.07.2020

Öztürkoğlu Budak, S., Figge, M.R., Houbraken, J., Vries, R.P. (2016). The diversity and evolution of microbiota in traditional Turkish Divle Cave cheese during ripening. Int Dairy J, 58: 50-53. https://doi.org/10.1016/j.idairyj.2015.09.011

Petyaev, I.M., Bashmakov, Y.K., 2012. Could cheese be the missing piece in the French paradox puzzle?. Med Hypotheses, 79, 746-749. https://doi.org/10.1016/j.mehy.2012.08.018

Perrone, G., Susca, A., (2017). Penicillium species and their associated mycotoxins. In: Mycotoxigenic Fungi: Methods and Protocols. Ed.: Moretti, A. ve Susca, A.., Humana Press Springer Protocols, 1st edition, New York.

Renaud, S., de Lorgeril, M., (1992). Wine, alcohol, platelets, and the French paradox for coronary heart disease. Lancet, 339: 1523-1526. https://doi.org/10.1016/0140-6736(92)91277-f 
Ropars, J., Dupont, J., Fontanillas, E., Rodriguez de la Vega, R.C., Malagnac, F., Coton, M., Giraud, T., L_opez-Villavicencio, M., (2012). Sex in cheese: evidence for sexuality in the fungus Penicillium roqueforti. PLoS One, 7(11): 7e49665. https://doi.org/10.1371/journal.pone.0049665

Ropars, J., Lopez-Villavicencio, M., Dupont, J., Snirc, A., Gillot, G., Coton, M., Jany, J.-L., Coton, E., Giraud, T., (2014). Induction of sexual reproduction and genetic diversity in the cheese fungus Penicillium roqueforti. Evol Appl, 7(4): 433441. https://doi.org/10.1111/eva.12140

Ropars, J., de la Vega, R.C.R., LopezVillavicencio, M., Gouzy, J., Sallet, E., Dumas, E., Lacoste, S., Debuchy, R., Dupont, J., Branca, A., Giraud, T., (2015). Adaptive horizontal gene transfers between multiple cheesee-associated fungi. Curr Biol, 25(19): 2562-2569. https://doi.org/10.1016/j.cub.2015.08.025

Ropars, J., De la Vega, R.R., Villavicencio, M.L., Branca, A. (2016a). Diversity and mechanisms of genomic adaptation in Penicillium. In: Aspergillus and Penicillium in the Post-Genomic Era, Ed.; DeVries, R.G., Andersen, M.R., Caister Academic Press: Lyngby, Denmark, pp. 27-42.

Ropars, J., Lo, Y.-C., Dumas, E., Snirc, A., Begerow, D., Rollnik, T., Lacoste, S., Dupont, J., Giraud, T., L_opez-Villavicencio, M., (2016b). Fertility depression among cheese-making Penicillium roqueforti strains suggests degeneration during domestication. Evolution, 70: 2099e2109. https://doi.org/10.1111/evo.13015
Ropars, J., Lopez-Villavicencio, M., Snirc, A., Lacoste, S., Giraud, T., (2017). Blue cheesemaking has shaped the population genetic structure of the mould Penicillium roqueforti. PLoS One, 12(3): e0171387. https://doi.org/10.1371/journal.pone.0171387

Schaack, S., Gilbert, C., Feschotte, C. (2010). Promiscuous DNA: horizontal transfer of transposable elements and why it matters for eukaryotic evolution. Trends Ecol Evol, 25(9): 537546. https://doi.org/10.1016/j.tree.2010.06.001

Seri, M. (2020). Konya küflü peynirinden izole edilen küflerin moleküler identifikasyonu ve Penicillium roqueforti izolatlarının morfolojik karakterizasyonu. İstanbul Sabahattin Zaim Üniversitesi, Fen Bilimleri Enstitüsü, G1da Mühendisliği Anabilim Dalı, Yüksek lisans tezi, İstanbul, $102 \mathrm{~s}$.

Şengün, I.Y., Yaman, D.B., Gönül, S.A., (2008). Mycotoxins and mould contamination in cheese: a review. World Mycotoxin J., 1(3): 291-298. https://doi.org/10.3920/WMJ2008.x041

Visagie, C.M., Houbraken, J., Frisvad, J.C., Hong, S.B., Klaassen, C.H.W., Perrone, G., Seifert, K.A., Varga, J., Yaguchi, T., Samson, R.A., (2014). Identification and nomenclature of the genus Penicillium. Stud Mycol, 78: 343-371. https://doi.org/10.1016/j.simyco.2014.09.001

Yalman, M., Tepeli, S.Ö., Demirel Zorba, N.N. (2016). Türkiye'de geleneksel yöntemlerle üretilen peynirlerin küf florass. Türk Tarm - Gıda Bilim ve Teknoloji Dergisi, 4(11): 926-933. 